\title{
вмЈ Global Health Environmental health practitioners: a key cadre in the control of COVID-19 in sub-Saharan Africa
}

\author{
Tracy Morse (1) , ${ }^{1,2}$ Kondwani Chidziwisano, ${ }^{1,2}$ David Musoke (D) ,3,4 \\ Tara K Beattie, ${ }^{1}$ Selva Mudaly ${ }^{5,6}$
}

To cite: Morse $\mathrm{T}$, Chidziwisano K, Musoke D, et al. Environmental health practitioners: a key cadre in the control of COVID-19 in sub-Saharan Africa. BMJ Global Health 2020;5:e03314. doi:10.1136/ bmjgh-2020-003314

Received 1 July 2020 Accepted 4 July 2020

\section{Check for updates}

(c) Author(s) (or their employer(s)) 2020. Re-use permitted under CC BY-NC. No commercial re-use. See rights and permissions. Published by BMJ

${ }^{1}$ Department of Civil and Environmental Engineering, University of Strathclyde, Glasgow, UK

${ }^{2}$ Department of Environmental Health, University of Malawi Polytechnic, Blantyre, Southern Region, Malawi

${ }^{3}$ School of Public Health, Makerere University College of Health Sciences, Kampala, Uganda

${ }^{4}$ Africa Academy for Environmental Health, School of Public Health, Makerere University, Kampala, Uganda ${ }^{5}$ International Federation of Environmental Health, Chartered Institute of Environmental Health, London, UK

${ }^{6}$ South African Institute of Environmental Health, Durban, Kwa Zulu Natal, South Africa

Correspondence to Dr Tracy Morse

tracy.thomson@strath.ac.uk
Early in 2020, as the novel severe acute respiratory syndrome coronavirus 2 (SARS-CoV-2) took a global hold, Kapata and colleagues asked the question 'Is Africa prepared and equipped to deal with yet another outbreak of a highly infectious disease - COVID-19?'. The authors advocated that, in many ways, the continent has never been better prepared to deal with a global pandemic, such as COVID19, having learnt and developed plans from previous and ongoing disease outbreaks, for example, Ebola in 2014-2016. However, in a region where health systems are already crippled by the delivery of routine health services, and where COVID-19 mitigation measures such as social distancing and lockdowns are neither physically nor economically viable, it is essential that we focus on context appropriate preventive measures to minimise the impact of SARS-CoV-2 transmission..$^{2-5}$

Key to the implementation of preventive measures are environmental health practitioners (EHPs). EHPs have played a vital role since the initial response to COVID-19 in sub-Saharan Africa (SSA), leading the rapid implementation of controls at border posts, for example, traveller screening, implementation of quarantining rules, isolation of cases and contact tracing through their role in port and community health management. However, as the number of cases across the continent continues to rise, it can be argued that EHPs have a much wider role to play due to their broad range of core functions and an array of specialisms focused on preventive health.

As described by the WHO, 'Environmental health addresses all the physical, chemical, and biological factors external to a person, and all the related factors impacting behaviours. It encompasses the assessment and control of those environmental factors that can potentially affect health. It is targeted

\section{Summary box}

- The multidisciplinary nature of environmental health practitioners (EHP) allows them to understand where different sectors can intersect to maximise severe acute respiratory syndrome coronavirus 2 (SARSCoV-2)-related interventions.

- EHPs have the necessary skills to support the transdisciplinary approach required to halt the further spread of SARS-CoV-2.

- Governments should support the work of EHPs across the region and include them among key decision-making stakeholders.

towards preventing disease and creating health-supportive environments' ${ }^{6}$ In the African context, these roles have been consolidated into five interlinked pillars, as outlined in figure $1 .^{7}$

Located within local authorities, primarily under the directorship of the ministries of health, EHPs manage these services through the principles of risk assessment and management to address adverse environmental influences on health, improve the health of the community and contribute to sustainable development.

The main role of EHPs in this pandemic is not just to provide expertise in the five pillars but also to exploit their ability to see where these areas intersect, and where an intervention in one area can lead to maximum impact across the whole population. For example, in the simplest terms, in order to ensure hygiene practices, a household needs access to water, but to have water available, a household must visit a communal water point where it may be difficult or impossible to practice social distancing or disinfection of hand contact surfaces after each use to minimise risk of SARS-CoV-2 transmission. Managing and mitigating this risk requires a holistic view which can coordinate a transdisciplinary response, 


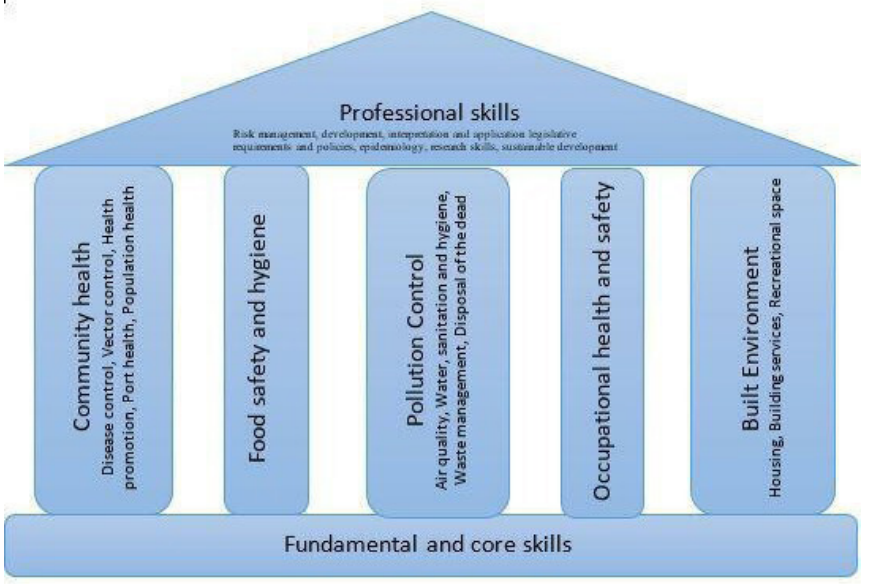

Figure 1 Five pillars of environmental health (adapted from Africa Academy for Environmental $\mathrm{Health}^{7}$ ).

engaging both experts and community members. As EHPs in SSA are commonly placed in health worker roles at both facility and community levels, they have a unique overview and relationship with the populations they serve to identify and address these scenarios. This positioning allows them to understand community dynamics and social and cultural norms, and enables rapid scale-up of interventions through a trusted voice, rapid identification and management of potential cases, and alleviation of myths and concerns regarding the disease. Within these settings, EHPs are key in the maintenance of infection prevention programmes and promotion of water, sanitation and hygiene practices and facilities, both of which are integral in SARS-CoV-2 control. They also support the provision of routine health services and through their community relationships can address issues of stigma and fear, which may reduce the willingness of households to attend such services, a challenge which may have longlasting repercussions on population health. ${ }^{8}$

EHPs are vital to the prevention of SARS-CoV-2 transmission in the population through the implementation of hygiene measures, using both infrastructure and hygiene promotion (behaviour change communication) to maximise the opportunity for improved and sustained behaviours. ${ }^{4}$ For example, hand washing with soap has been promoted for decades in low-income settings but has attained minimal progress due to a reported lack of access to water, soap and handwashing facilities. ${ }^{9}$ However, with the urgency of COVID-19, EHPs can use lessons from recent studies which have successfully promoted and sustained effective hand washing with soap in these resource-limited settings. ${ }^{10}{ }^{11}$ Using EHPs to promote hygiene, for example, through sensitisation and demonstration of proper handwashing procedures, not only can impact the trajectory of the current pandemic but also can be leveraged as an opportunity to increase effective hygiene behaviours in the long term.

The ever-expanding database of publications related to SARS-CoV-2 also highlights a plethora of areas, both in research and implementation, where EHPs can provide both expertise and generalism and use this opportunity to leverage long-term context appropriate improvements, in what are often neglected areas. For example, (1) the isolation of viral particles in faeces and wastewater highlights the importance of water, sanitation and hygiene programmes to minimise infection transmission ${ }^{12}{ }^{13}$; (2) concerns regarding the management of SARS-CoV2-related healthcare waste, which will require on site treatment ${ }^{14}$; (3) strengthening control of informal, commercial, institutional and domestic food safety, particularly with regard to meat hygiene, direct consumption of raw produce from markets (which may be in contact with river water contaminated with faeces due to poor sanitation), and the preparation and consumption of street foods (informal vendors) ${ }^{15}$; and (4) the need for effective health and safety guidance for the assurance of safe work and institutional environments, taking into consideration both physical and mental wellbeing, including social distancing measures, disinfection procedures, ventilation, and appropriate sanitation and hygiene facility provision. ${ }^{16}$

Issues surrounding the control of infections such as SARS-CoV-2 are complex and wicked in nature. To tackle current and future pandemic situations, we require to take a transformative approach to preventive health, and in a world where the majority of qualifications are now narrow and specialised, EHPs bring a broad spectrum of skills which allows them to 'dance across disciplines'. ${ }^{17}$ The EHP can become the lynch pin by which both preventive and control measures are implemented in resourcelimited settings such as SSA, leading a transdisciplinary approach which examines the risks associated with each exposure pathway, weighing the pros and cons of each to provide context appropriate intervention development.

The success of this approach requires recognition, investment and support of the EHP workforce. It is essential that they are effectively trained, supported and provided with the necessary materials and tools such as transportation, communication, protective equipment and educational materials to engage with their communities. In a time where rapid response is essential and face-to-face interaction must be minimised, this means further innovation using mobile devices, social media, and online platforms for both training provision and hygiene promotion delivery. Innovation in this area will allow the development of methods which can be more effective for future campaigns in reaching high numbers within low-resource settings.

With an overarching, holistic range of skills, EHPs offer not only an essential but also a unique role in the prevention and control of diseases such as COVID-19 in SSA. However, for them to do this, it is essential that governments support the work of EHPs across the region and include them among key decision-making stakeholders. Twitter Tracy Morse @nyanitm and David Musoke @DavidMusoke14

Contributors TM developed the concept and draft of the commentary. KC, TKB, DM and SM contributed to the content and editing. 
Funding The authors have not declared a specific grant for this research from any funding agency in the public, commercial or not-for-profit sectors.

Competing interests None declared.

Patient consent for publication Not required.

Provenance and peer review Not commissioned; internally peer reviewed.

Data availability statement There are no data in this work.

Open access This is an open access article distributed in accordance with the Creative Commons Attribution Non Commercial (CC BY-NC 4.0) license, which permits others to distribute, remix, adapt, build upon this work non-commercially, and license their derivative works on different terms, provided the original work is properly cited, appropriate credit is given, any changes made indicated, and the use is non-commercial. See: http://creativecommons.org/licenses/by-nc/4.0/.

\section{ORCID iDs}

Tracy Morse http://orcid.org/0000-0003-4185-9471

David Musoke http://orcid.org/0000-0003-3262-3918

\section{REFERENCES}

1 Kapata N, Ihekweazu C, Ntoumi F, et al. Is Africa prepared for tackling the COVID-19 (SARS-CoV-2) epidemic. lessons from past outbreaks, ongoing pan-African public health efforts, and implications for the future. Int J Infect Dis 2020;93:233-6.

2 Ataguba JE. COVID-19 pandemic, a war to be won: understanding its economic implications for Africa. Appl Health Econ Health Policy 2020;18:325-8.

3 Sumner A, Hoy C, Ortiz-Juarez E. Estimates of the impact of COVID-19 on global poverty. WIDER Working Paper 2020.

4 Curtis V. Strategic thinking in a pandemic: a blueprint for Government-LedNational hygiene communication campaigns to combat COVID-19 2020.
5 Cabore JW, Karamagi HC, Kipruto H, et al. The potential effects of widespread community transmission of SARS-CoV-2 infection in the world Health organization African region: a predictive model. BMJ Glob Health 2020;5:e002647.

6 WHO. Definition of environmental health, 2000. Available: http:// origin.searo.who.int/topics/environmental_health/en/ [Accessed 29 Jun 2020].

7 Africa Academy for Environmental Health. Environmental health curriculum, 2010. Available: https://www.ifeh.org/afa/docs/AAEH\% 20curriculum\%20April\%202010\%20Rev01.pdf

8 Nelson R. COVID-19 disrupts vaccine delivery. Lancet Infect Dis 2020;20:546.

9 Brauer M, Zhao JT, Bennitt FB, et al. Global access to handwashing: implications for COVID-19 control in low-income countries. Environ Health Perspect 2020;128:57005.

10 Gautam OP, Schmidt W-P, Cairncross S, et al. Trial of a novel intervention to improve multiple food hygiene behaviors in Nepal. Am J Trop Med Hyg 2017;96:1415-26.

11 Chidziwisano K, Slekiene J, Mosler H-J, et al. Improving complementary food hygiene behaviors using the risk, attitude, norms, ability, and self-regulation approach in rural Malawi. Am J Trop Med Hyg 2020;102:1104-15.

12 Quilliam RS, Weidmann M, Moresco V, et al. COVID-19: the environmental implications of shedding SARS-CoV-2 in human faeces. Environ Int 2020;140:105790.

13 Caruso BA, Freeman MC. Shared sanitation and the spread of COVID-19: risks and next steps. Lancet Planet Health 2020;4:e173.

14 Tilley E, Kalina M. "We Are Already Sick": Infectious Waste Management and Inequality in the Time of Covid-19, a Reflection from Blantyre, Malawi. Worldwide Waste. J Interdiscip Stud 2020;3:3.

15 WHO. COVID-19 and food safety: guidance for competent authorities responsible for national food safety control systems 2020.

16 WHO. Getting your workplace ready for COVID-19 2020.

17 Epstein D. Range - How Generalists Triumph in a Specialised World, ed. MacMillan, 2019. 